\title{
POTENCIAL DE RIZOBACTÉRIAS NO CRESCIMENTO DE MUDAS DE SIBIPIRUNA (Caesalpinia peltophoroides BENTH) ${ }^{1}$
}

Jeane de Fátima Cunha ${ }^{2}$, Acelino Couto Alfenas ${ }^{3}$, Aderlan Gomes da Silva ${ }^{4}$ e Isac Jonatas Brandão ${ }^{5}$

\begin{abstract}
RESUMO - Este trabalho objetivou avaliar o potencial de isolados de rizobactérias na germinação de sementes e no crescimento de mudas de sibipiruna (Caesalpinia peltophoroides). Testaram-se os isolados pré-selecionados para eucalipto, Ca, FL2, MF2, MF4, RC3, R1, 3918, S1, S2 e CIIB. Para tanto, amostras de substrato à base de vermiculita e casca de arroz carbonizada (1:1) foram tratados com $5 \mathrm{~mL}$ de uma suspensão de cada isolado $\left(\mathrm{OD}_{540}=0,2 \mathrm{~A}\right) /$ tubete de $55 \mathrm{cc}$ de capacidade, correspondendo a cerca de $10 \mathrm{ufc} / \mathrm{mL}$. O delineamento experimental foi inteiramente casualizado (DIC) com cinco repetições por tratamento, com 20 sementes cada. Aos 40 dias, avaliaram-se a porcentagem de germinação e a massa seca de raízes e da parte aérea. Verificou-se aumento significativo em matéria seca de raiz e da parte aérea para todos os isolados de rizobactérias testados, em relação à testemunha. Todos os isolados proporcionaram aumento significativo na germinação, à exceção do 3918 e CIIB que não diferiram da testemunha. Entre os isolados testados, quatro destacaram-se como os mais promissores (FL2, MF4, MF2 e CIIB). Os resultados obtidos mostram ganhos significativos na produção de mudas, sem nenhum ajuste no manejo ou na estrutura do viveiro. Além desse ganho direto, pode-se ter um melhor aproveitamento da estrutura física dos viveiros, ao se diminuir o tempo de formação das mudas, reduzindo-se o custo de produção.
\end{abstract}

Palavras-chave: Sementes, PGPR, Produção de mudas.

\section{EPOTENTIAL OF RHIZOBACTERIAS FOR THE GROWTH OF SEEDLINGS OF SIBIPIRUNA (Caesalpinia peltophoroides BENTH)}

\begin{abstract}
The objective of this work was to evaluate the potential of growth-promoting rhizobacteria for seed germination and biomass of the root system and aerial part of seedlings of sibipiruna (Caesalpinia peltophoroides). Isolates pre-selected for eucalyptus were used, Ca, FL2, MF2, MF4, RC3, R1, 3918, S1, S2 and CIIB. Thus, samples of vermiculite-based substrate and carbonized rice hull (1:1) were treated with $5 \mathrm{~mL}$ of a suspension of each isolate $\left(O D_{540}=0.2 \mathrm{~A}\right) /$ tubette of $55 \mathrm{cc}$ capacity corresponding to around $10 \mathrm{ufc} / \mathrm{mL}$. The experimental design was completely randomized (CRD) with five repetitions per treatment, each constituted by 20 seeds. At 40 days, germination percentage and dry mass of the roots and the aerial parts were evaluated. A significant increase was observed in dry matter of the root and aerial part for all the rhizobacteria isolates tested, compared to the control. All the isolates provided significant germination increase, except 3918 and CIIB, which did not differ from the control. Among the tested isolates, four were the most promising (FL2, MF4, MF2 and CIIB). The results obtained show significant gains in seedling production, without any adjustment in nursery management or structure. In addition to this direct gain, it is possible to make a better use of the physical structure of the nurseries by reducing the time needed for seedling formation, reducing the production costs.
\end{abstract}

Keywords: Seeds, PGPR, Seedling production.

\footnotetext{
${ }^{1}$ Recebido em 07.12.2011 aceito para publicação em 09.04.2013.

${ }^{2}$ Programa de Pós-graduação em Ciência Florestal na Universidade Federal de Viçosa, UFV, Brasil. E-mail:<jeanefcunha@ yahoo.com.br>.

${ }^{3}$ Departamento de Fitopatologia, Universidade Federal de Viçosa, UFV, Brasil. E-mail:<aalfenas@ufv.br>.

${ }^{4}$ Instituto Federal de Educação, Ciência e Tecnologia de Minas Gerais, Campus de São João Evangelista. E-mail:<aderlan@yahoo.com.br>.

${ }^{5}$ Faculdade de Ciências Gerenciais de Manhuaçu, FACIG, Brasil. E-mail:<isacbrand@ yahoo.com.br>.
} 


\section{INTRODUÇÃO}

Atualmente, no Brasil, tem sido grande a preocupação com a conservação de espécies florestais nativas, e o seu uso vem sendo restringido e também protegido por lei no intuito de impedir a destruição das florestas brasileiras (SIRVINSKAS, 2012).

Poucos estudos existem a respeito de produção de mudas de espécies nativas, ao contrário da cultura do eucalipto, que vem tomando espaço no Brasil devido ao desenvolvimento de pesquisas, como melhoramento genético e utilização de rizobactérias (TEIXEIRA et al., 2007).

Mudas de espécies nativas têm sido utilizadas para diversas finalidades, como reflorestamentos e arborização (CARVALHO, 2010). A utilização de espécies nativas para reflorestamento de áreas desmatadas é de grande importância para reduzir o impacto ambiental causado pelos desmatamentos e conservar a biodiversidade. Entre as espécies ornamentais destinadas à arborização urbana, pode-se citar: pata de vaca (Bauhinia forficata), sibipiruna (Caesalpinia peltophoroides), ipê-amarelo-anão (Tecoma stans), flamboyant-anão (Caesalpinia pulcherrima) e murta (Murraya paniculata) (LORENZI, 2009).

A sibipiruna é originária da Mata Atlântica brasileira. É encontrada em todas as regiões do Brasil, mas existe com mais intensidade no litoral entre Bahia e Rio de Janeiro. A sibipiruna, além de ser recomendada para o paisagismo urbano, pode ser cultivada em parques e jardins e indicada para recuperação de áreas degradadas como espécie secundária inicial ou pioneira; sua madeira pode, também, ser usada para construção civil, como caibros e ripas, para estrutura de móveis e caixotaria em geral (LORENZI, 2009).

Para o sucesso desejado na implantação de projetos de reflorestamento, bem como arborização, é importante que as mudas sejam bem formadas, com maior resistência a doenças bióticas e abióticas, possibilitando melhor desempenho em condições de campo. Assim, técnicas alternativas que otimizem a germinação das sementes e o crescimento de espécies nativas são fundamentais para melhorar a qualidade das mudas e reduzir o custo de produção. Nesse aspecto, as rizobactérias ganham destaque, pois podem propiciar a produção de mudas melhores.
Rizobactérias são bactérias da rizosfera com capacidade de colonizar as raízes das plantas na presença da microbiota natural do solo (SCHOROTH; HANCOCK, 1982). A interação entre bactérias e raízes de plantas pode ser benéfica, prejudicial ou neutra (SCHIPPERS et al., 1987). Rizobactérias benéficas são encontradas na rizosfera de diversas culturas, e 2 a $5 \%$ dos isolados dessas rizobactérias podem apresentar efeito positivo no crescimento de plantas (AHMAD et al., 2008). Aquelas que exercem efeito benéfico no desenvolvimento de plantas através da promoção do crescimento e, ou, proteção contra organismos patogênicos são chamadas de rizobactérias promotoras de crescimento de plantas ou Plant Growth-Promoting Rizobacteria (PGPR) (KLOEPPER et al., 1990). As rizobactérias que são prejudiciais às plantas, chamadas de Deleterious Rhizosphere Microorganisms (DRMO), colonizam as raízes e são consideradas patogênicas (SUSLOW; SCHROTH, 1982).

Entre as PGPR, destacam-se as dos gêneros Pseudomonas, principalmente do grupo fluorescente, Bacillus e actinomicetos do gênero Streptomyces; embora outros gêneros de bactérias sejam citados na literatura (Arthrobacter, Serratia, Azoarcus, Herbaspirillum, Gluconacetobacter, Klebsiella) (SPAEPEN et al., 2009).

Rizobactérias têm sido estudadas há vários anos devido à capacidade de aumentar o crescimento de plantas (BROWN, 1974; GLICK, 1995; SOLANOetal., 2008; HAYAT et al., 2010). Em essências florestais, observou-se o efeito de rizobactérias no crescimento de mudas oriundas de sementes como Pinus (BRUNETTA et al., 2010; MACIEL, 2012) e de clones de eucalipto (ZARPELON, 2007; MAFIA et al., 2009c).

Entre 107 isolados de bactérias obtidas da rizosfera de mudas de diferentes clones de eucalipto, 10 (Ca, FL2, MF2, MF4, RC3, R1, 3918, S1, S2 e CIIB) apresentaram potencial como promotores de enraizamento de estacas e miniestacas de Eucalyptus spp., proporcionando ganhos de $110 \%$ no enraizamento e de até $250 \%$ no peso de matéria seca de raízes de estacas e miniestacas, e os isolados FL2 e MF2 induziram resistência sistêmica à ferrugem causada por Puccinia psidii (TEIXEIRA et al., 2007). Apesar dos resultados positivos obtidos no referido trabalho, poucos estudos têm sido realizados testando o efeito de rizobactérias em espécies nativas. 
Devido aos resultados de Eucalyptus spp., aliados às necessidades de novas tecnologias para produção de mudas de espécies nativas, objetivou-se avaliar o potencial de isolados de rizobactérias na germinação de sementes e no crescimento de mudas de sibipiruna (Caesalpinia peltophoroides).

\section{MATERIAL E MÉTODOS}

A pesquisa foi conduzida no Laboratório de Patologia Florestal e Genética da Interação Planta Patógeno do Departamento de Fitopatologia/Bioagro e no viveiro de Pesquisa Florestal do Departamento de Engenharia Florestal, da Universidade Federal de Viçosa (Viçosa, MG), no período de 16/07/2010 a 25/09 de 2010.

Foram testados 10 isolados de rizobactérias em suspensão salina. As sementes de sibipiruna (Caesalpinia peltophoroides) utilizadas foram coletadas na Mata da Silvicultura da Universidade Federal de Viçosa (Viçosa, MG).

Testaram-se os isolados de rizobactérias préselecionados para eucalipto (TEIXEIRA et al., 2007), sendo eles: FL2 (Pseudomonas aeruginosa), Ca (Pseudomonas fulva), 3918 (Bacillus subtilis), R1 (Frauteria aurantia), S1 (Bacillus subtilis), S2 (Bacillus subtilis), CIIB (Stenotrophomonas maltophilia), MF2 (Pseudomonas sp.), MF4 (Pseudomonas sp.) e VC2 (não identificado).

\subsection{Produção e preparo do inóculo}

A suspensão de cada rizobactéria foi preparada no Laboratório de Patologia Florestal e Genética da Interação Planta Patógeno do Departamento de Fitopatologia/Bioagro a 0,2 de absorbância aferida em espectrofotômetro a $540 \mathrm{~nm}$, equivalente a $10^{8}$ ufc (unidades formadoras de colônias)/mL. Para a produção do inóculo, suspensões bacterianas em solução salina $(0,85 \%)$ foram obtidas a partir de colônias cultivadas em meio 523 de Kado e Reskett (1970) por 48 h a $27^{\circ} \mathrm{C}$ (MAFIA et al., 2007). A fim de confirmar a concentração de inóculo aplicada e a viabilidade das células bacterianas, em cada ensaio foi reservada uma alíquota de cada suspensão para posterior avaliação em espectrofotômetro.

Ao inóculo em suspensão salina foi adicionada $1 \%$ de leite em pó como fonte alimentar inicial para as rizobactérias. A suspensão de inóculo dos respectivos isolados, equivalente a $5 \mathrm{~mL}$ de suspensão por $50 \mathrm{cc}$ (centímetros cúbicos) de substrato, foi aplicada no substrato e homogeneizada em caixas de plástico.

\subsection{Rizobacterização do substrato}

Para a rizobacterização do substrato, utilizaram-se 11 caixas plásticas. Em 10, aplicaram-se 5 L de substrato (vermiculita: casca de arroz carbonizada (1:1)), 0,5 L da suspensão do inóculo (5 mL/tubete) a 0,2 de absorbância $\left(10^{8} \mathrm{ufc} / \mathrm{mL}\right)$ contendo cada rizobactéria, diluído em 0,5 L de água, 0,04 g de superfosfato simples e $1 \%$ de leite em pó. Na testemunha, o substrato foi tratado com água ( $1 \mathrm{~L})$ e superfosfato simples $(0,04 \mathrm{~g})$. Em cada tratamento foram utilizados 100 tubetes plásticos de $50 \mathrm{~mL}$ de capacidade.

O substrato inoculado foi homogeneizado e distribuído nos tubetes montados em bandejas de 96 células devidamente etiquetadas por repetição e tratamento. Cada bandeja continha 60 tubetes, com a exceção de uma, que continha 20. As bandejas foram levadas para casa de vegetação, onde se procedeu à semeadura de duas sementes em cada tubete. Airrigação foi feita duas vezes por dia (manhã e tarde), utilizando-se o sistema de irrigação por aspersão. Após 40 dias, avaliou-se o experimento.

\subsection{Variáveis avaliadas}

Foram avaliados a porcentagem de germinação e o peso de matéria seca de raízes e da parte aérea aos 40 dias.

Para avaliação da porcentagem de germinação, foram contadas todas as sementes germinadas, por tratamento e repetição. Para determinação do peso de matéria seca de raízes e da parte aérea, as raízes e parte aérea de 10 plantas de cada repetição foram destacadas, lavadas e colocadas em sacos de papel, secas em estufa a $70{ }^{\circ} \mathrm{C}$ por $72 \mathrm{~h}$ e pesadas.

\subsection{Procedimentos estatísticos}

O ensaio foi montado em delineamento experimental inteiramente casualizado (DIC), contendo 11 tratamentos (10 rizobactérias +1 testemunha) com cinco repetições de 20 mudas cada, totalizando 1.100 plantas.

As análises estatísticas foram feitas no programa SAEG, sendo as médias comparadas pelo teste de Scott Knott a 5\% de significância.

Revista Árvore, Viçosa-MG, v.37, n.2, p.211-218, 2013 


\section{RESULTADOS}

Verificou-se aumento significativo na matéria seca de raízes e da parte aérea para todos os isolados de rizobactérias testados, em relação à testemunha. Para porcentagem de germinação, a maioria dos isolados diferiu significativamente da testemunha, à exceção do 3918 e CIIB. Apesar disso, o índice de germinação para esses isolados foi numericamente maior, comparando-se com a testemunha (Tabela 1).

Apesar de não ter havido diferença estatística na maioria dos isolados, o FL2 foi numericamente superior aos demais, para porcentagem de germinação, pois aumentou em $36,8 \%$ o número de sementes germinadas, enquanto o $\mathrm{S} 2$ promoveu um ganho de $35,6 \%$. Utilizando o isolado FL2, também se obteve boa resposta para peso de matéria seca de raízes e da parte aérea. Apesar de o isolado CIIB não ter diferido estatisticamente da testemunha e do 3918 quanto à porcentagem de germinação, para matéria seca de raízes, ele foi significativamente superior à testemunha e numericamente superior aos demais isolados. Para matéria seca da parte aérea, o ganho obtido com o isolado MF4 foi numericamente superior, comparando-se com os demais isolados. Para matéria seca de raízes, o ganho obtido com o isolado MF4 foi inferior apenas ao obtido com o isolado CIIB. Com o isolado FL2, também se obtiveram boas respostas quanto ao incremento de matéria seca de raízes e parte aérea.

Para os isolados significativamente superiores à testemunha, os ganhos em germinação variaram de $21,8 \%$ a 36,8\%, com uma média de $29,3 \%$. Já para matéria seca da parte aérea os ganhos variaram de $20,0 \%$ a $36,3 \%$, com média de $27,2 \%$, enquanto para matéria seca de raiz foram obtidos ganhos de $66,7 \%$ a $105,7 \%$, com média de $83,6 \%$.

\section{DISCUSSÃO}

Isolados de rizobactérias veiculados no substrato aumentaram a germinação das sementes, a altura e o peso da matéria seca da parte aérea e do sistema radicular de mudas seminais de sibipiruna. Muitos autores relataram o envolvimento de rizobactérias no crescimento do sistema radicular, da parte aérea e do potencial germinativo de várias culturas (MAFIA et al., 2007; SOUZA JÚNIOR, 2010; MACIEL, 2012). Em essências florestais, observou-se o efeito de rizobactérias no crescimento de mudas oriundas de sementes de Pinus, Picea, Tsuga, Pseudotsuga

Tabela 1 - Porcentagem de sobrevivência, peso da matéria seca do sistema radicular e da parte aérea de 10 mudas de sibipiruna (Caesalpinia peltophoroides) aos 40 dias, para os isolados FL2, S2, Ca, VC2, MF4, MF2, S1, R1, 3918 e CIIB.

Table 1 - Percentage of survival, dry matter weight of the root system and aerial part of 10 Sibipiruna seedlings (Caesalpinia peltophoroides) to 40 days for isolates FL2, S2, Ca, VC2, MF4, MF2, S1, R1, 3918 and CIIB.

\begin{tabular}{|c|c|c|c|c|c|c|c|c|}
\hline \multirow{3}{*}{$\begin{array}{c}\text { Isolados } \\
\text { FL2 }\end{array}$} & \multicolumn{8}{|c|}{ Variáveis } \\
\hline & \multicolumn{2}{|c|}{ Sobrevivência (\%) } & \multicolumn{3}{|c|}{ Matéria seca de raiz (mg) } & \multicolumn{3}{|c|}{ Matéria seca da parte aérea $(\mathrm{mg})$} \\
\hline & 59,5 a & $(36,8)$ & 788 & $\mathrm{a}$ & $(87,6)$ & 2140 & $\mathrm{a}$ & $(33,8)$ \\
\hline S2 & 59,0 a & $(35,6)$ & 700 & $\mathrm{a}$ & $(66,7)$ & 2040 & a & $(27,5)$ \\
\hline $\mathrm{Ca}$ & 59,0 a & $(35,6)$ & 718 & $\mathrm{a}$ & $(70,9)$ & 1930 & $\mathrm{a}$ & $(20,6)$ \\
\hline $\mathrm{VC} 2$ & 56,0 a & $(28,7)$ & 756 & $\mathrm{a}$ & $(80,0)$ & 2000 & $\mathrm{a}$ & $(25,0)$ \\
\hline MF4 & 55,5 a & $(27,6)$ & 860 & $\mathrm{a}$ & $(104,7)$ & 2180 & $\mathrm{a}$ & $(36,3)$ \\
\hline MF2 & 54,5 a & $(25,3)$ & 796 & $\mathrm{a}$ & $(89,5)$ & 2120 & $\mathrm{a}$ & $(32,5)$ \\
\hline $\mathrm{S} 1$ & 53,5 a & $(22,9)$ & 710 & $\mathrm{a}$ & $(69,0)$ & 2078 & $\mathrm{a}$ & $(29,9)$ \\
\hline $\mathrm{R} 1$ & 53,0 a & $(21,8)$ & 760 & $\mathrm{a}$ & $(80,9)$ & 1980 & $\mathrm{a}$ & $(23,8)$ \\
\hline 3918 & 51,5 b & - & 760 & $\mathbf{a}$ & $(80,9)$ & 1920 & $\mathbf{a}$ & $(20,0)$ \\
\hline CIIB & $51,0 \quad$ b & - & 864 & $\mathbf{a}$ & $(105,7)$ & 1960 & $\mathbf{a}$ & $(22,5)$ \\
\hline Test. & $43,5 \mathrm{~b}$ & - & 420 & $\mathrm{~b}$ & - & 1600 & $\mathrm{~b}$ & - \\
\hline Ganh. médios (\%) & 29,3 & 83,6 & 27,2 & & & & & \\
\hline Coef. de Variação(\%) & 12,5 & 12,9 & 12,3 & & & & & \\
\hline
\end{tabular}

Revista Árvore, Viçosa-MG, v.37, n.2, p.211-218, 2013 
(CHANWAY, 1992) e abeto-vermelho (CHANWAY; HOLL, 1993). Brunetta et al. (2010) observaram ganhos que variaram de 10 a $16 \%$ no crescimento em altura da parte aérea de mudas de Pinus, e Maciel (2012) verificou incremento no potencial germinativo de sementes de Pinus quando microbiolizadas com Bacillus subtilis.

Algumas pesquisas com eucalipto indicaram altas taxas de ganhos devido ao emprego de rizobactérias, principalmente, para matéria seca do sistema radicular. Mafia et al. (2009c) verificaram incrementos de 187,6\% na biomassa radicular de clone híbrido de eucalipto após a inoculação com rizobactérias. Teixeira et al. (2007) destacaram que vários isolados de rizobactérias atuaram como excelentes indutores de enraizamento de estacas e miniestacas de Eucalyptus spp., promovendo ganhos de até $110 \%$ no enraizamento médio e $250 \%$ no peso de matéria seca de raiz. Mafia et al. (2007) observaram ganhos de 20,4\% no enraizamento e de $73 \%$ na biomassa radicular de clones de eucalipto quando inoculados com isolados de rizobactérias em diferentes condições de propagação clonal. Resultados semelhantes foram encontrados neste trabalho, em que os ganhos de matéria seca do sistema radicular variaram de $66,7 \%$ a $105,7 \%$.

Rizobactérias também atuaram no crescimento de espécies agronômicas, como arroz (SOUZA JÚNIOR, 2010), feijão (GARCIA, 2008) e tomate (PELZER, 2010). Apesar de os estudos com rizobactérias envolverem várias culturas, poucos estudos existem avaliando o seu potencial na germinação e no crescimento de mudas de espécies nativas.

Embora Schrot e Hancock (1982) tenham relatado que isolados promotores de crescimento em uma espécie de planta podem não ser efetivo para outra, isso não foi observado em Eucalyptus spp. e sibipiruna. Os resultados indicaram que os mesmos isolados selecionados para eucalipto por Teixeira et al. (2007) e que aumentaram a biomassa de clones de Eucalyptus spp. também apresentaram grande potencial para incremento de biomassa de mudas seminais de sibipiruna. Isso quer dizer que os isolados de rizobactérias extraídos da região da rizosfera de mudas de Eucalyptus spp. não são específicos dessa espécie, podendo ser utilizados para aumento de biomassa de mudas de sibipiruna e também apresentando potencial para a realização de testes com outras espécies nativas e também agronômicas.
Dos 10 isolados testados, sete são dos gêneros mais comumente relatados como promotores de crescimento, Pseudomonas e Bacillus (TEIXEIRA et al., 2007; SPAEPEN et al., 2009). Neste trabalho, em geral, os isolados que mais se destacaram foram os do gênero Pseudomonas (MF2 e MF4). Em outros trabalhos, também foi observado o efeito de isolados de Pseudomonas no crescimento de plantas. Em testes realizados com Pseudomonas fluorescentes em Citrus: limão-rugoso (Citrus jambhiri) e laranja-doce (C. sinensis), verificou-se estímulo no crescimento de plantas da ordem de $116 \%$, após 10 meses da inoculação (GARDNER et al., 1984). Neves et al. (2004) observaram incrementos de $67 \%$ na biomassa da parte aérea e $120 \%$ na biomassa do sistema radicular de mudas de Hovenia dulcis (uva-do-japão) quando tratadas com um isolado de Pseudomonas (MF2). Em estacas de Eucalyptus spp., constatou-se incremento de 62,8\% no enraizamento e $24 \%$ na matéria seca do sistema radicular quando essas estacas foram tratadas com um isolado de Pseudomonas (TEIXEIRA, 2001).

Os isolados de rizobactérias podem ter agido de formas direta ou indireta no crescimento de mudas de sibipiruna. Em mecanismos indiretos, as rizobactérias atuariam com agentes de biocontrole, suprimindo organismos deletérios ou patogênicos às plantas, ou beneficiando organismos benéficos a elas. Muitas vezes, o efeito negativo de um microrganismo sobre a planta ocorre de forma dificilmente perceptível, não ocorrendo infecção ou aparecimento de sintomas típicos, como os induzidos por organismos patogênicos (TEIXEIRA, 2001). Geralmente, esses microrganismos afetam a planta por meio da produção de metabólitos tóxicos, e seus efeitos se restringem à diminuição do desenvolvimento em razão de atuarem negativamente sobre os processos de germinação, brotação e enraizamento (SCHIPPERS et al., 1987). Embora ainda não totalmente esclarecido, o efeito direto no crescimento de plantas provavelmente decorre da produção de fitormônios como auxinas e giberelinas, inibição da síntese de etileno e mineralização de nutrientes (HAYAT et al., 2010).

Embora a determinação dos mecanismos de promoção não fosse objeto deste estudo, é provável que a produção de fitormônio, síntese de etileno e solubilização de fosfato estejam envolvidos. Os isolados bacterianos presentes no solo são, em sua maioria, capazes de produzir AIA (SPAEPEN et al., 2009). Um mutante de $P$. fluorescens super produtor de AIA estimulou o 
desenvolvimento radicular de estacas de groselheirapreta (DUBEIKOVSKY et al., 1993). A produção de AIA por rizobactérias também foi observada em estudos com tomateiro(PELZER, 2010) e orquídeas (TSAVKELOVA et al., 2007), demonstrando que é um mecanismo que atua na promoção do crescimento de plantas. Além disso, o efeito dos isolados pode ocorrer não só pela produção direta de auxinas, mas também via estímulo à síntese desses fitormônios, pela própria planta (HAYAT et al., 2010).

Outro mecanismo direto que poderia estar envolvido no crescimento de mudas de sibipiruna seria a inibição da síntese de etileno. Segundo Haal et al. (1996), um dos mecanismos mais importantes envolvidos na promoção de crescimento de plantas por rizobactérias é a capacidade desses organismos em diminuir o nível endógeno de etileno nas plantas. O etileno pode atuar como indutor de enraizamento em várias espécies, no entanto o seu acúmulo apresenta efeito inibitório na posterior elongação das raízes (TEIXEIRA, 2001).

O fósforo, elemento pouco móvel no solo, é um dos principais elementos que pode ter sua absorção aumentada com a utilização de rizobactérias não só pela capacidade de alguns isolados solubilizarem esse elemento (VENIERAKI et al., 2010), como também em decorrência da maior área de solo explorada pelo sistema radicular mais bem desenvolvido (TEIXEIRA, 2001). Vários estudos têm examinado a habilidade de diferentes espécies bacterianas em solubilizar compostos fosfatados inorgânicos insolúveis, como fosfato tricálcio, fosfato dicálcio, hidroxiapatita e fosfato rochoso (FARINA, 2012). De acordo com esse autor, entre os gêneros com essa capacidade estão Bacillus e Pseudomonas, que foram os isolados utilizados neste trabalho.

O uso de rizobactérias promotoras de crescimento de plantas (PGPRs) durante a fase de produção de mudas de espécies nativas tende a ser alternativa com grande probabilidade de sucesso, podendo propiciar, ao mesmo tempo, aumento da germinação de sementes e maior crescimento de mudas.

\section{CONCLUSÃO}

Verificou-se aumento significativo da matéria seca de raiz e da parte aérea de todos os isolados de rizobactérias testados, em relação à testemunha. Todos os isolados proporcionaram aumento significativo na germinação, à exceção do 3918 e CIIB, que não diferiram da testemunha. Entre os isolados testados, quatro destacaram-se como os mais promissores (FL2, MF4, MF2 e CIIB).

Diante dos resultados, isolados de rizobactérias podem ser recomendados para otimizar a produção de mudas de sibipiruna, pois aumentaram tanto a porcentagem de sobrevivência das sementes quanto, também, o peso de matéria seca do sistema radicular e da parte aérea, além do que a rizobacterização não demanda mudanças na rotina de produção de mudas nos viveiros.

Com os resultados deste trabalho, também se abre um leque para que rizobactérias sejam testadas em outras espécies nativas, agregando maior valor ao produto formulado. O uso de rizobactérias promotoras de crescimento de plantas (PGPRs) durante a fase de produção de mudas de espécies nativas tende a ser alternativa com grande probabilidade de sucesso.

\section{REFERÊNCIAS}

AHMAD, F.; AHMAD, I.; KHAN, M. S. Screening of free-living rhizospheric bacteria for their multiple plant growth promoting activities. Microbial Research, v.163, p.173-181, 2008.

BROWN, M. E. Seed and root bacterization. Annual Review of Phytopathology, v. 12, p.181-197, 1974.

BRUNETTA, J. M. F. C. et al. Isolamento e seleção de rizobactérias promotoras do crescimento de Pinus taeda. Revista Árvore, v.34, n.3, p.399-406, 2010.

\section{CARVALHO, P. E. R. Espécies arbóreas} brasileiras. São Paulo: Embrapa, 2010. v.4. 644 .

CHANWAY, C. P. Influence of soil biota on Douglas-fir Pseudotsuga menziesii seedling growth: the role of rhizhosphere bacteria. Canadian Journal of Botany, v.70, p.1025-1031, 1992.

CHANWAY, C. P.; HOLL, F. B. First year field performance of spruce seedlings inoculated with plant growth promoting rhizobacteria.

Canadian Journal of Microbiology, v.39, n.11, p.1084-1088, 1993. 
DUBEIKOVSKY, A. N. et al. Growth promotion of blackcurrant softwood cuttings by recombinant strain Pseudomonas fluorescens BSP53a synthetisizing an increased amount of indole-3acetic-acid. Soil Biological Biochemical, v.25, n.9, p.1277-1281, 1993.

FARINA, R. Diversidade de bactérias promotoras do crescimento vegetal associadas à cultura de canola (Brassica napus L.) cultivada no município de Vacaria, Rio Grande do Sul. 2012. 104 f. Tese (Doutorado em Genética e Biologia Molecular) - Universidade Federal do Rio Grande do Sul, Porto Alegre, 2012.

GARCIA, F. A. Biocaracterização de procariotas como agentes de biocontrole de enfermidades e promotores de crescimento em feijoeiro. 2008. 132f. Tese (Doutorado em Fitopatologia) - Universidade Federal de Viçosa, Viçosa, MG, 2008.

GARDNER, J. M.; CHANDLER, J. L.; FELDMAN, A. W. Growth promotion and inhibition by antibiotic-producing fluorescent pseudomonads on citrus roots. Plant and Soil, v.77, p.103$113,1984$.

GLICK, B. R. The enhancement of plant growth by free-living bacteria. Canadian Journal Microbiology, v.41, n.2, p.109-117, 1995.

HALL, J. A. et al. Root elongation in various agronomic crops by plant growth promoting rhizobacterium Pseudomonas putida GR12-2.

Journal Plant Science, v.44, n.1, p.37-41, 1996.

HAYAT, R. et al. Soil beneficial bacteria and their role in plant growth promotion: a review. Annals of Microbiology, v.60, p.579-598, 2010.

KADO, C. I.; HESKETT, M. S. Selective media for isolation of Agrobacterium, Corynebacterium, Erwinea, Pseudomonas and Xanthomonas.

Pythopathology, v.60, n.6, p.969-976, 1970.

KLOEPPER, J. W.; ZABLOTOWICZ, R. M.;

LIFSHITZ, R. Plant growth-promoting mediated by rhizosphere colonizers. In: KEISTER, D. L.; CREGAN, P. B. (Ed.). The rhizosphere and plant growth. Dordrecht: Academic Publishers, 1990. p.315-326.
LORENZI, H. Árvores brasileiras: manual de identificação e cultivo de plantas arbóreas nativas do Brasil. Nova Odessa: Instituto Plantarum, 2009. v.3. 286p.

\section{MACIEL, C. G. Fusarium sambucinum} associado a sementes de pinus elliottii: patogenicidade, morfologia, filogenia molecular e controle. 2012. 93f.

Dissertação (Mestrado em Engenharia Florestal) Universidade Federal de Santa Maria, Santa Maria, 2012.

MAFIA, R. G. et al. Efeito de rizobactérias sobre o enraizamento e crescimento de clones de eucalipto em diferentes condições de propagação clonal. Revista Árvore, v.31, n.5, p.813-821, 2007.

MAFIA, R. G. et al. Microbiolização e interação entre rizobactérias promotoras do crescimento e clones de eucalipto. Revista Árvore, v.35, n.5, p.789-797, 2009.

NEVES, I. F. et al. Rizobactérias como promotoras do crescimento de espécies arbóreas ornamentais. In: SIMPÓSIO DE INICIAÇÃO CIENTÍfICA, 14., 2004, Viçosa, MG. Anais... Viçosa, MG: 2004. p.153.

PELZER, G. Q. Mecanismo de controle da murcha-de-esclerócio e promoção de crescimento em tomateiro mediados por rizobactéria. 2010. 64f. Dissertação (Mestrado em Agronomia) - Universidade Federal de Roraima, Boa Vista, 2010.

SCHROTH, M. N.; HANCOCK, J. Disease suppressive soil and root colonizing bacteria. Science, v.216, n.4553, p.1376-1381, 1982.

SCHIPPERS, B. et al. Beneficial and deleterious and beneficial rhizosphere microorganims and the effect og cropping practices. Annual Review of Phytophatology, v.5, p.339358, 1987.

SOLANO, B. R.; MAICAS, J. B.; MANERO, F. J. G. Phisiological and molecular mechanisms of plant growth promoting rhizobacteria (PGPR). In: AHMAD, I.; PICHTEL, J; HAYAT, S (Ed.). Plant-bacteria interactions: strategies and techniques to promote plant growth. Weinheim: Wiley, 2008. p.41-52.

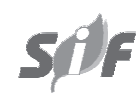

Revista Árvore, Viçosa-MG, v.37, n.2, p.211-218, 2013 
SOUZA JUNIOR, I. T. Controle biológico de doenças do arroz: ampliação do espectro de ação e promoção de crescimento pelo uso de combinações de rizobactérias eficientes. 2010. 67f. Dissertação (Mestrado em Fitossanidade) Universidade Federal de Pelotas, Pelotas, 2010.

SIRVINSKAS, L. P. Manual de direito ambiental. 10.ed. São Paulo: Saraiva, 2012. p.798.

SPAEPEN, S.; VANDERLEYDEN, J.; OKON, O. Plant growth-promoting actions of rizobactheria. Advances in Botanical Research, v.51, n.2, p.283-320, 2009.

SUSLOW, T. V.; SCHROTH, M. N. Role of deleterious rhizobacterias as minor pathogens in reducing crop growth. Phytophatology, v.72, n.1, p.111-115, 1982.

TEIXEIRA, D. A. et al. Rhizobacterial promotion of eucalypt rooting and growth. Brazilian Journal of Microbiology, v.38, n.1, p.118-123, 2007.
TEIXEIRA, D. A. Promoção de enraizamento e indução de resistência sistêmica à ferrugem à mancha de Cylindrocladium, mediadas por rizobactérias em clones de Eucalyptus spp.. 2001. 67f. Dissertação (Doutorado em Fitopatologia) - Universidade Federal de Viçosa, Viçosa, MG, 2001.

TSAVKELOVA, E. A. et al. Bacteria associated with orchid roots and microbial production of auxin. Microbiological Research, v.162, n.1, p.69-76, 2007.

VENIERAKI, A. et al. The genetic diversity of culturable nitrogen-fixing bacteria in the rhizosphere of wheat. Microbial Ecology, v.61, n.2, p.277-285, 2010.

\section{ZARPELON, T. G. Caracterização de} rizobactérias e eficiência do Rizolyptus ${ }^{\circledR}$ no enraizamento e crescimento do eucalipto. 2007. 69f. Dissertação (Mestrado em Fitopatologia) - Universidade Federal de Viçosa, Viçosa, MG, 2007. 